\title{
Depósitos Pleistocênicos e Holocênicos associados a contextos arqueológicos de ar livre no Alto Ribatejo
}

\author{
Pierluigi Rosina*, Hugo Gomes**, Pedro P. Cunha***
}

Palavras-chave: Paleolítico-

Neolítico; Agropastoralismo; Sedimentologia.

Keywords: PalaeolithicNeolithic; Agropastoralism; Sedimentology.
Resumo: Os estudos arqueológicos sugerem padrões tecnológicos e de liquidação de recorrências e/ou convergências durante a transição do Pleistoceno-Holoceno. A fim de compreender melhor a sequência de ocupações humanas na região do Alto Ribatejo do Tejo inferior, um estudo geoarqueológico foi realizado, incluindo a caracterização sedimentológica de depósitos, a análise estratigráfica e a sua ligação com os contextos arqueológicos. O estudo sedimentar envolveu trabalhos de campo e de laboratório (análises de tamanho de grão e difração de raios X de agregados orientados para a identificação de minerais de argila). Um amplo espaço de tempo foi considerado, à procura de possíveis tendências dentro de uma determinada região de Portugal, o Alto Ribatejo. A fim de resolver esta questão, foram realizados estudos em diferentes depósitos: fluviais, coluviais, eólicos, eluviais e de origem antrópica. Este artigo apresenta os resultados de um estudo com base principalmente em sítios arqueológicos de ar livre que pertencem a diferentes fases culturais: do Paleolítico Superior, Epipaleolítico, Neolítico e Calcolítico. Os dados apoiam a interpretação de que as condições de clima frio do intervalo $~ 32$ a $12 \mathrm{ka}$, gerando principalmente sedimentos coluviais e depósitos eólicos. Condições húmidas ou secas (temperadas) que levaram a mudanças nas paisagens culturais durante o Holoceno.

Abstract: Archaeological studies suggest technological standards and settlement of recurrences and/or convergence during the Pleistocene-Holocene transition. In order to better understand the sequence of human occupation in the Alto Ribatejo region of the lower Tagus, one geoarchaeological study was conducted, including sedimentological characterization of the deposits, stratigraphic analysis and its connection with the archaeological contexts. The study involved field work and laboratory analysis (grain size analysis and X-ray diffraction of aggregates, directed to the identification of clay minerals). A large amount of time was considered for possible long-term trends within a particular region of Portugal, the Alto Ribatejo (Middle Portuguese Tagus). In order to address this issue, field surveys were carried out in different deposits: fluvial, colluvial, aeolian, eluvials and anthropic. This article presents the results of a study based mainly in open air archaeological sites belonging to different cultural phases: the Upper Palaeolithic, Epipaleolithic / Mesolithic, Neolithic and Chalcolithic. The data support the interpretation that the cold weather conditions the range $\sim 32$ to $12 \mathrm{ka}$, generating mainly colluvial sediments and aeolian deposits. Wet or dry conditions (temperate) led to changes in cultural landscapes during the Holocene.

\footnotetext{
* Professor adjunto no Instituto Politécnico de Tomar. Graduou-se em Geologia na Sapienza, em Roma, em 1997, DEA (mestrado) em Geologia do Quaternário em Perpignan, França, em 2001, doutor sobre o tema da Meio-ambiente, comportamento e dinâmica humana na Universidade de Ferrara, na Itália, em 2004. Membro da Unidade de I \& D do Centro de Geociências - Grupo de Quaternário e Pré-História da Universidade de Coimbra - Faculdade de Ciências e Tecnologia (uID 73). Participa de vários projetos europeus e nacionais com pesquisas nas áreas da geoarqueologia e arqueometria em Portugal, Espanha, Itália, África (Angola, Senegal e Etiópia) e América do Sul (Brasil). E-mail: prosina@ipt.pt.

** Licenciado em Geologia e Mestre em Geociências (dissertação em geoarqueologia) pela Universidade de Coimbra, Doutor em Quaternário Materiais e Culturas (tese em arqueometria) pela Universidade de Trás-os-Montes e Alto Douro. Investigador do Grupo Quaternário e Pré-História do Centro de Geociências. E-mail: hugo.hugomes@gmail.com.

***Professor Catedrático de Geologia no Departamento de Ciências da Terra - Universidade de Coimbra. Licenciado em Geologia, Doutorado em Estratigrafia, Paleontologia e Geoistória, e Agregado em Geologia, pela Universidade de Coimbra. Investigador do Centro de Ciências do Mar e do Ambiente (MARE). Realiza investigação em Estratigrafia, Sedimentologia, Geomorfologia, Neotectônica, Geoarqueologia e Datação por Luminescência. Estudou diversificados registos sedimentares do Jurássico ao Quaternário e um amplo contexto de ambientes deposicionais (fluviais a marinhos). Tem mais de uma centena de artigos em revistas e livros científicos. E-mail: pcunha@dct.uc.pt.
} 


\section{Enquadramento do Território}

A área de estudo enquadra-se na subregião do Alto Ribatejo correspondente ao Ribatejo Norte, distrito de Santarém, integrando-se na bacia hidrográfica portuguesa do rio Tejo. Trata-se de um território de confluência de diferentes unidades geológicas e geomorfológicas (Figura 1) cujos limites fisiográficos não são muito evidentes, sendo o rio Tejo o elemento característico que concretiza a continuidade territorial. Esta denominação geográfica - Médio Tejo - refere-se somente ao troço português deste rio, de Belver até Tancos (RIBEIRO; LAUTENSACH; DEVEAU, 1991), enquanto do ponto de vista estritamente geomorfológico, todo o percurso do rio Tejo português pode ser considerado o Baixo Tejo (MARTINS et al., 2009) na bacia hidrográfica peninsular.

A área ribeirinha do Médio Tejo português é constituída por algumas zonas de inundação delimitadas por relevos que geralmente não ultrapassam os 200 metros e apresentam uma morfologia em planalto, na qual se encaixam, por vezes de forma escarpada, os cursos de água. Esse processo de encaixe dos rios encontra-se testemunhado pelos vales com terraços e coluviões (Quaternário) e as serras que delimitam esta área atingem os 600 metros de altitude (Figura 1).
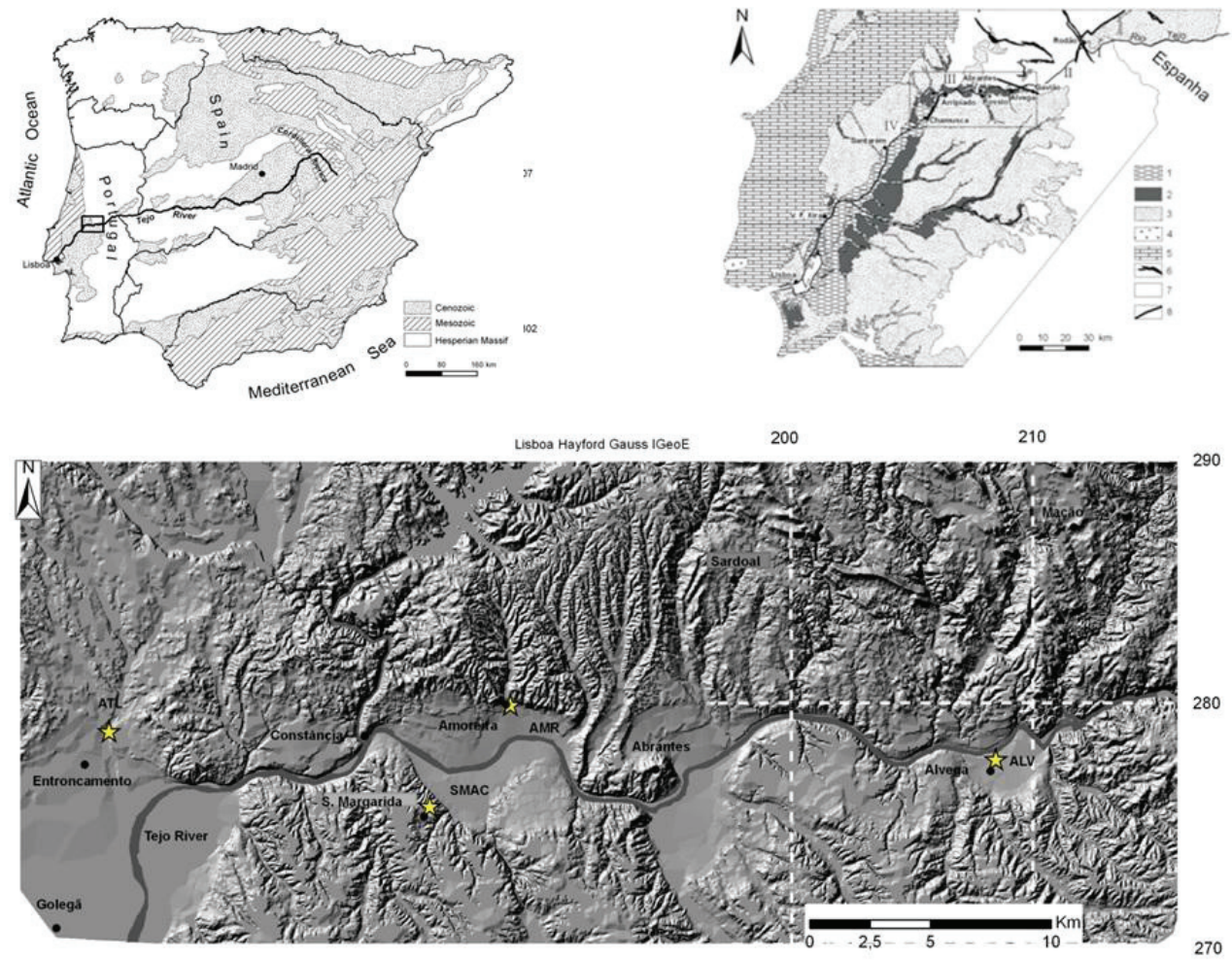

Figura 1 - Modelo altimétrico do terreno do Alto Ribatejo e localização geográfica dos contextos analisados Legenda: Ribeira da Atalaia, Amoreira, Santa Margarida da Coutada, Anta 1 Vale da Laje, Monumento 5 da Jogada, Anta da Lajinha, Alvega.

Fonte: Elaborada pelos autores (2010).

As características geomorfológicas desta região estão estritamente relacionadas com os diferentes tipos de substrato: as cristas são tipicamente quartzíticas, as zonas de encaixe ocorrem nos xistos e granitos, os terraços a as planícies de inundação coincidem com o substrato argiloarenoso, enquanto os fenômenos cársicos estão obviamente relacionados com os afloramentos calcários. Os depósitos mais recentes (quaternários) que encerram os vestígios arqueológicos e paleoambientais no Alto Ribatejo são constituídos por sedimentos de origem eólica, coluvionar e/ou eluvial, aluvial e de enchimento de grutas.

O rio Tejo é o maior rio navegável da Península Ibérica, com aproximadamente $1.007 \mathrm{~km}$ 
de extensão e uma bacia de $86.000 \mathrm{~km}^{2}$; e cerca de $70 \%$ desta área está localizada na Espanha e 30\% em Portugal $\left(\sim 24.850 \mathrm{~km}^{2}\right)$.

O regime hídrico do Tejo sofreu alterações ao longo do Holocênico, conforme as oscilações climáticas que se refletiram em períodos de maior ou menor caudal/inundação (VIS et al., 2010a, 2010b).

A observação das linhas de água e seus percursos permitem-nos vislumbrar corredores de passagem que, a partir do Tejo enquanto eixo central, permitiam o acesso a todo o interior da Península Ibérica, bem como às Beiras e ao Alto Alentejo.

\section{Geologia e Geomorfologia}

É um território de confluência entre três unidades geológicas e geomorfológicas (Figura $1 \mathrm{e}$ Figura 2): a) formações detríticas da Bacia Sedimentar Terciária do Tejo-Sado; b) Maciço Hespérico (xistos, quartzitos e granitos); c) Maciço Calcário Estremenho. Estas unidades morfoestruturais estão assim repartidas: ao centro e a Sul estendem-se os depósitos mais recentes da bacia Cenozoica do Tejo que é delimitada a W e NW pelo Maciço Calcário Estremenho, com rochas essencialmente do Mesozoico. Entre o E e NW afloram o Grupo DúricoBeirão e Granitoides Paleozoicos e Pré-Câmbricos do Maciço Hespérico. O relevo está orientado segundo a Cordilheira Central Portuguesa (NE-SW) (GONÇALVES et al., 1979).

O Grupo da Beiras (antigamente designado por Complexo Xisto-Grauváquico) comportase como terreno metamórfico impermeável e a rede hidrográfica é densa e emaranhada. O aspeto característico destas regiões é traduzido por séries de colinas de cumes arredondados com altitudes semelhantes. A estrutura dos xistos facilita largamente a sua alteração, resultando como produto final as argilas.

O Maciço Calcário Estremenho (M. C. E.), representado na Orla Ocidental, assume-se como um mosaico de rochas de diversas idades, sendo constituído predominantemente por calcários do Jurássico e arenitos principalmente Cretácicos.

$\mathrm{O}$ registo sedimentar do Mesozoico compreende formações de rochas carbonatadas, como os calcários, as margas e as dolomias, ou detríticas, como argilas e os arenitos. Em áreas de calcários, a dissolução constrói formas características como lapiás, algares, dolinas, grutas, poljes, planaltos secos e gargantas estreitas; deixa para trás o resíduo insolúvel (argila e areia) de cor vermelho, designado por "terra rossa".

Identificaram-se seis níveis de terraços ( $\mathrm{T} 1$, T2, T3, T4, T5 e T6). Os três inferiores possuem material arqueológico (ROSINA et al., 2014), e estão a ser escavados sedimentos pertencentes aos terraços T4, T5 e coluviões sobrejacentes que também contêm artefatos. Por isso, este sítio é importante não só na interpretação das fases culturais do Paleolítico como também das sequências de depósitos quaternários da região.

\section{Os depósitos da transição Pleistoceno-Holoceno}

Os depósitos sedimentares continentais estão fortemente influenciados pelas condições climáticas e ambientais. As oscilações climáticas Pleistocênicas e Holocênicas foram responsáveis pelas variações morfogenéticas associadas aos contrastes nas formas de meteorização, com reflexos diretos na tipologia dos depósitos correlativos. Desse modo, nas diferentes fases climáticas pode-se registar morfogênese mecânica, com pronunciada ou discreta pedogênese, ou períodos de meteorização química, com entalhe da drenagem e processos de coluvionamento.

O clima atual, caracterizado como continental atenuado (DAVEAU, 1995) é propício ao desenvolvimento florestal, à sobrevivência de uma fauna diversificada e à prática da agricultura.

No Alto Ribatejo, essa história deposicional resulta em acumulações de sedimentos de diferente origem: coluviões; depósitos eólicos; aluviões atuais e subatuais; depósitos de enchimento de cavidades cársicas; depósitos de origem antrópica; rególito (depósitos eluviais e iluviais).

Os depósitos eólicos existentes na área de estudo são testemunhos de alterações climáticas e ambientais (degradação da cobertura arbórea). Existem depósitos eólicos passíveis de serem correlacionados, frequentemente associados à superfície de terraços antigos, por exemplo, no sítio 
de Santa Cita (BICHO; FERRING, 2001; LUSSU et al., 2001), encerrando indústrias Epipaleolíticas.

Para o efeito deste estudo, consideramos depósitos antrópicos todos os contextos cujos sedimentos não se depositaram naturalmente ou que foram de tal forma alterados tornando impossível obter resultados comparáveis com as restantes análises sedimentológicas.

\section{Metodologia}

Do ponto de vista laboratorial, efetuou-se a caracterização de sedimentos de sítios atribuídos e/ou datados do final do Pleistoceno até idades históricas. Os dados aqui tratados foram obtidos a escalas muito diversas: desde a escala regional, com o estudo e interpretação de cartas ou dos registos de sondagens e escavações, à da natureza de uma fração granulométrica, com a determinação da mineralogia da fração argilosa ou do tamanho dos grãos.

No campo realizaram-se prospecções, reconhecimento e identificação das sequências estratigráficas e recolha de amostras. Em laboratório, foram feitas as análises granulométricas das rochas sedimentares não consolidadas, com aplicação de metodologia laser ou, ainda, a caracterização mineralógica da fração argilosa por DRX.

Uma vez obtida a distribuição do tamanho dos grãos, o sedimento pôde ser caracterizado por vários parâmetros: tamanho médio, moda, mediana, calibragem, curtose e assimetria.

A maior parte dos sítios têm perfis de reduzida expressão vertical e apresentam obviamente bastante influência antrópica.

\section{Sítios analisados}

Os estudos sedimentológicos foram efetuados em sítios arqueológicos escavados ou em curso de escavação, compreendendo diferentes tipologias (ar livre e monumentos megalíticos) e cronologias (desde o Pleistocênico final até idades Históricas). Também se realizaram análises em depósitos naturais para obter dados de referência com o intuito de descriminar os depósitos naturais das acumulações de origem antrópica.

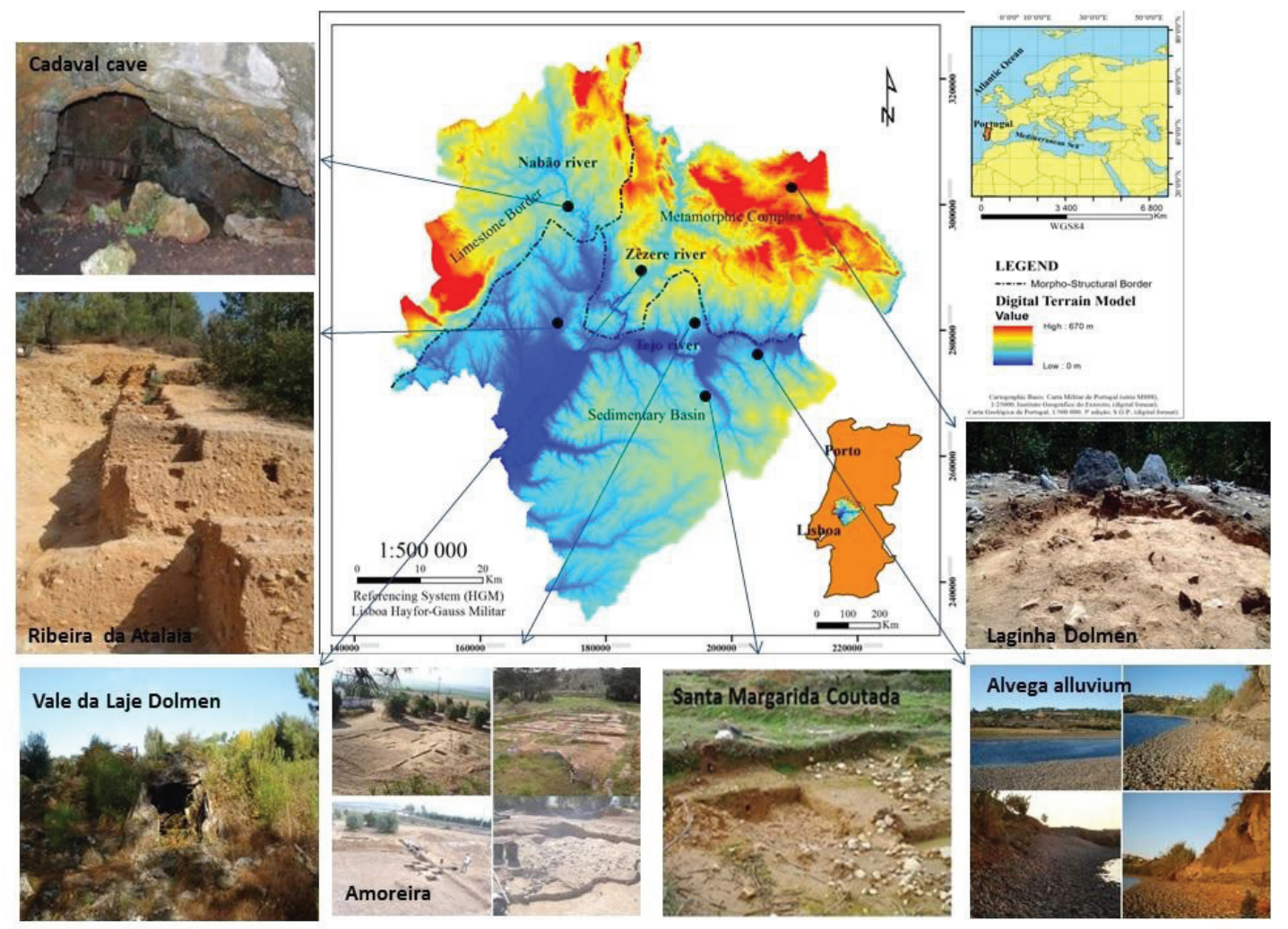

Figura 2 - Mapa localização dos sítios analisados no Alto Ribatejo, Portugal Central Fonte: Elaborada pelos autores (2010) 


\section{Ocupações de ar livre}

\section{Ribeira da Atalaia}

O sítio arqueológico da Ribeira da Atalaia, também conhecido como Ribeira da Ponte da Pedra, contém os depósitos mais antigos analisados (Pleistoceno final). Localizado à margem esquerda da Ribeira da Atalaia e a poucos quilômetros da confluência desta com o Rio Tejo, encontra-se no concelho de Vila Nova da Barquinha, com as coordenadas 39²8 $2633^{\prime \prime} \mathrm{N}$; 8²7'43 94”W.

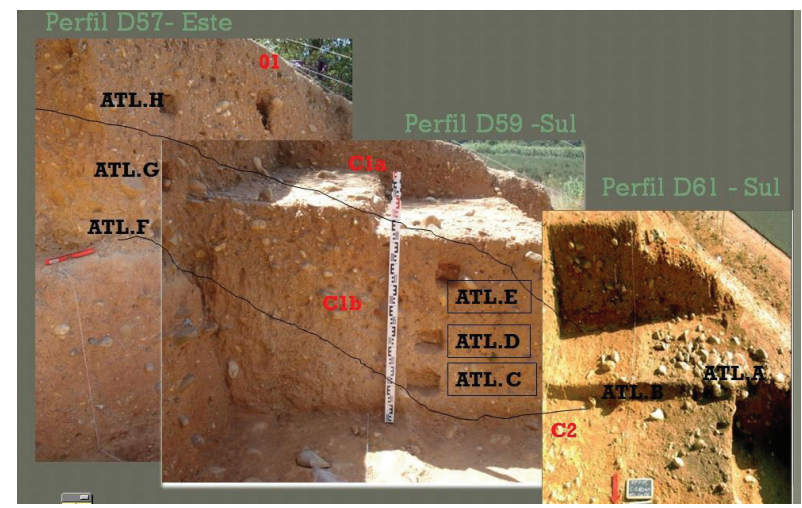

Figura 3 - Depósitos coluvionares da Ribeira da Atalaia, com localização das amostras recolhidas para análise sedimentológica

Fonte: Elaborada pelos autores (2010)

O sítio arqueológico situa-se em uma vertente do vale exposta a oeste, entre 50 e $30 \mathrm{~m}$ de altitude, constituído por depósitos fluviais e coluviões. Foi identificada a seguinte sequência de referência: substrato Miocênico, base do terraço T4, topo do terraço T5 e depósitos coluvionares que recobrem os outros depósitos (Figura 3). Estes últimos foram alvo de investigação de pormenor, sendo os mais importantes para caracterizar a transição Pleistoceno/Holoceno. As escavações realizadas permitiram a recolha de milhares de artefatos líticos (CURA; GRIMALDI, 2009), visto que, nas coberturas coluvionares, foram registados até ao momento 2.694 artefatos líticos produzidos quase exclusivamente sobre quartzito, matéria-prima predominante nos depósitos de terraço. Em trabalhos anteriores (ROSINA et al., 2009), procedeu-se a descrição macroscópica das camadas coluvionares, dividindoas em camada superficial (solo atual), C1a e C1b, C2. Em 2005, após a descoberta de uma estrutura de combustão na base das coluviões, recolheram-se amostras de sedimentos e efetivaram-se datações absolutas (OSL e TL) nos depósitos coluvionares e na estrutura de combustão, tendo-se obtido datações de cerca de $25 \mathrm{ka}$ (DIAS et al., 2009).

\section{Amoreira}

O sítio arqueológico da Amoreira (AMR) encontra-se no concelho de Abrantes e localiza-se à margem direita do Tejo, na área de confluência da Ribeira da Pucariça a cerca de $25 \mathrm{~km}$ a Sudoeste de Mação - CMP no 331 e geológica 27-D (Abrantes).

O sítio está implantado sobre um terraço fluvial (T4) “[...] constituído por formações de seixos e calhaus embalados em depósitos predominantemente arenosos ocasionalmente arenosiltosos de cor alaranjada" (CRUZ; OOSTERBEEK, 2005). A estratigrafia arqueológica compõe-se por três camadas, A (revolvida), B (Idade do Bronze) e C (provavelmente Neolítica) (CURA et al., 2004). $\mathrm{A}$ análise dos materiais indicou que os materiais paleolíticos são provenientes, provavelmente, do topo da vertente (camada A revolvida) (Figura 4).

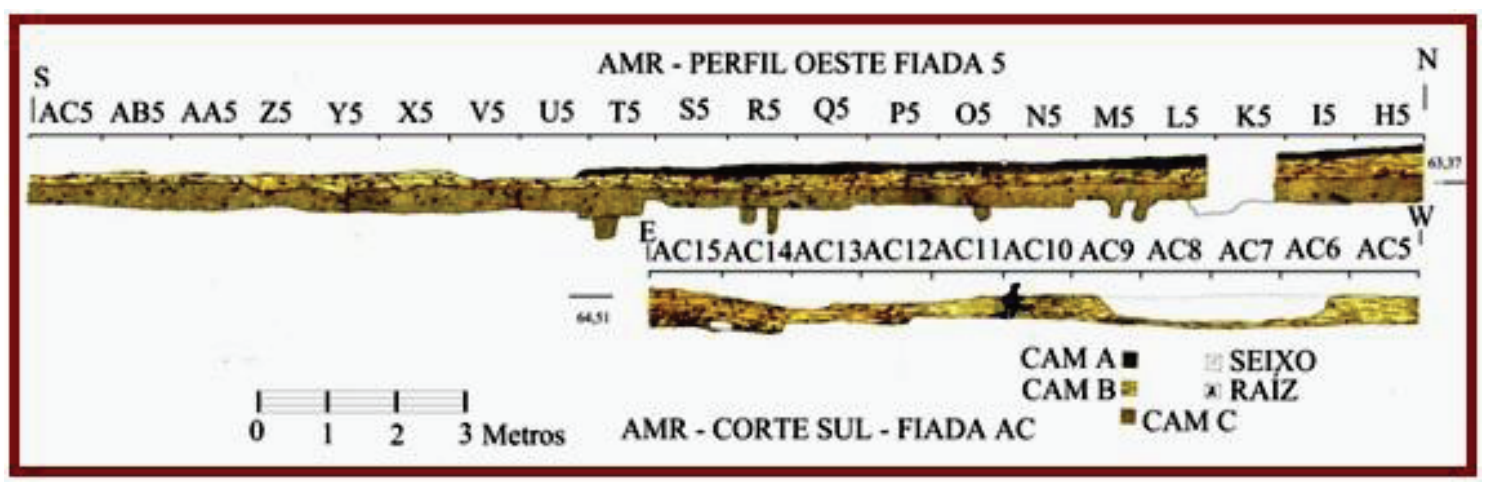

Figura 4 - Perfil estratigráfico do sítio arqueológico da Amoreira Fonte: Adaptada de Cruz (1995) 
O conteúdo arqueológico do sítio compreende estruturas tais como: buraco de poste de uma estrutura construída com madeira de pinheiro, de acordo com análises antracológicas (ALLUÉ, 2000); uma estrutura pétrea de combustão; duas lareiras de cozinha em fossa, artefatos espalhados sem organização; e duas áreas de talhe. Foram estudadas mais de 500 peças, em que o quartzito constitui a matéria-prima dominante, seguido do quartzo, escasso sílex e outros (CRUZ, 1995).

As datações disponíveis, efetuadas em carvões recolhidos na camada $\mathrm{C}$ deram como resultados 8280-8200 BC - AMS C ${ }^{14}$ (calibrado 2 sigma), 6706-6157 - $\mathrm{C}^{14}$ (calibrado 2 sigma). Foram sugeridas para este sítio ocupações da transição
Epipaleolítico/Mesolítico, Neolítico e Idade do Bronze (CRUZ, 1995; PEREIRA; CARVALHO, 2015).

\section{Santa Margarida da Coutada}

Situa-se no concelho de Constância, freguesia e Lugar de Aldeia de Santa Margarida da Coutada (SMAC) à altitude de $107 \mathrm{~m}$, tendo como coordenadas M- 39॰26'44 56"N, P- 8²7'43 94" W.

O sítio arqueológico de Santa Margarida da Coutada (SMAC), intervencionado desde 2006 (Figura 5) (CRUZ, 2006), está implantado em uma superfície de terraço (marcado como Q1 na carta geológica 27-D Abrantes; T2) inscrito na bacia Cenozoica do Tejo; o relevo é condicionado pela ação erosiva e pela tectónica orientada a N-S e NW-SE.

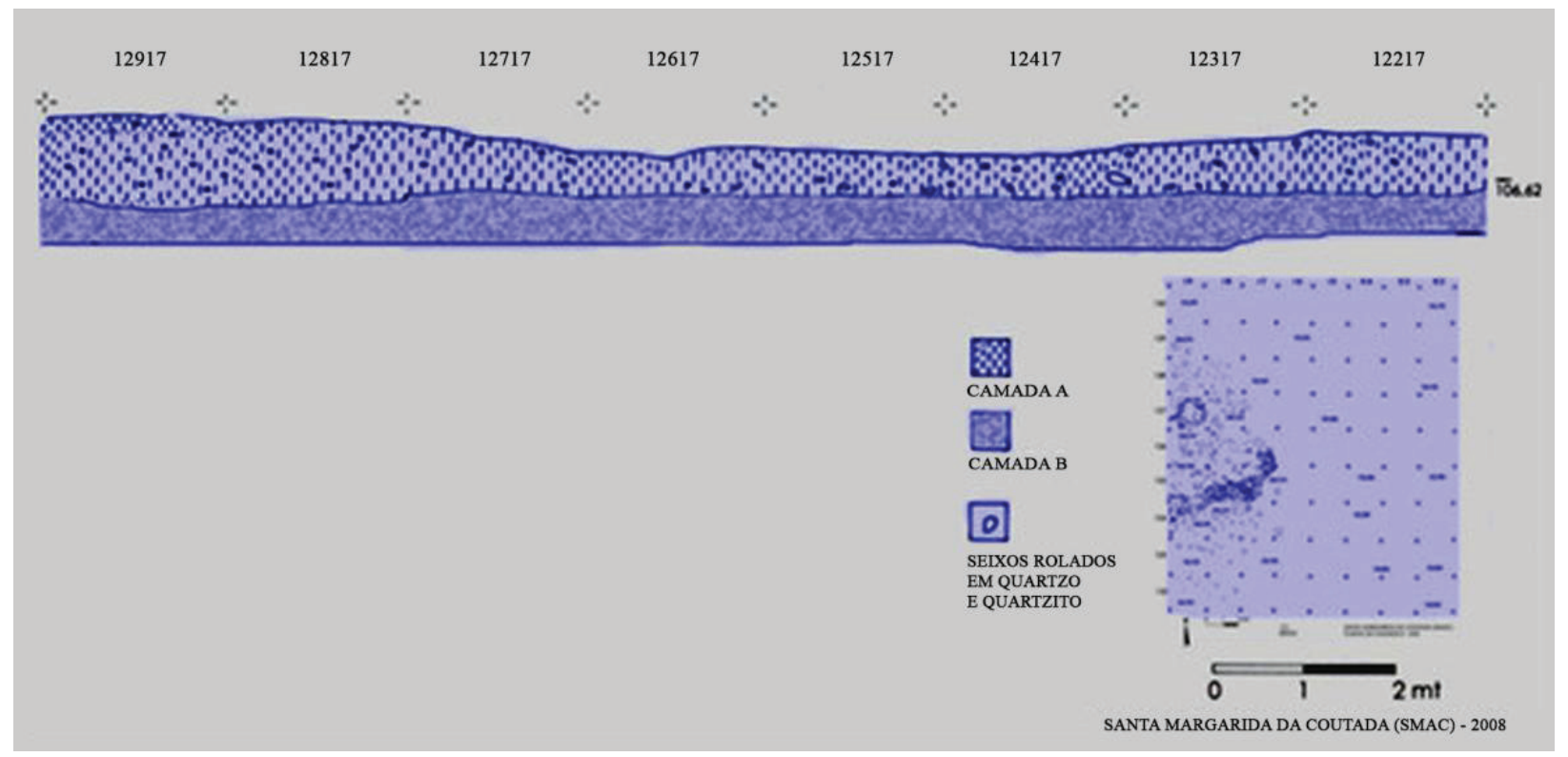

Figura 5 - Perfil estratigráfico do sítio arqueológico de Santa Margarida da Coutada Fonte: Adaptada de Cruz, 2006.

Neste povoado, os dados parecem apontar ocupações do Neolítico, Calcolítico e Bronze inicial, expressas por cerâmica cardeal, bordos espessos, cerâmica impressa, cerâmica com mamilos, machados de pedra polida, enxós, pesos de rede, pontas de seta de base côncava e triangular, fragmentos de vidro verde romano. Também se identificou material de época Paleolítica, como lâminas simples e retocadas, lamelas, furadores, bifaces, núcleos levallois e lascas e seixos talhados em quartzito.

\section{Monumentos Megalíticos}

\section{Anta 1 de Val da Laje}

A Anta 1 de Val da Laje, localizada no concelho de Tomar, insere-se no Vale do Zêzere com as coordenadas: $39^{\circ} 33^{\prime} 2288^{\prime \prime} \mathrm{N}, 8^{\circ} 18^{\prime} 0760^{\prime \prime} \mathrm{W}$. Corresponde a uma necrópole com quatro outros monumentos atualmente completamente destruídos. Situa-se no Maciço Hespérico, onde a diversidade 
geológica compreende xistos, quartzitos, granitos e gnaisses (CRUZ, 1997). Consiste em um pequeno monte, hoje com $1,75 \mathrm{~m}$ de altura e aproximadamente $10 \mathrm{~m}$ de comprimento (N-S), feito de terra e grande quantidade de pequenos blocos, com esteios em gnaisse e uma câmara pentagonal. O corredor é formado por dois esteios de cada lado e coberto por uma laje única (CRUZ, 1997; OOSTERBEEK, 1994; DREWETT et al., 1992).

Pode identificar-se que ocorreram vários momentos de ocupação não continuada; na sua segunda fase de construção à volta da câmara e do corredor, foi edificada uma cintura de pequenas lajes verticais separadas por seixos de quartzo e quartzito. A anta apresentava para além de cerâmicas, objetos em quartzito e quartzo, sobretudo sílex e anfibolito, testemunhando as redes de intercâmbio de matériasprimas que se foram estabelecendo na região. Não foram encontrados ossos, mas muitos artefatos (uma centena de cada tipo) que podem estar relacionados com rituais funerários (OOSTERBEEK, 2008).

\section{Anta da Laginha}

A Anta da Lajinha situa-se no Vale Pereiro, Cardigos, no concelho de Mação, entre o Moinho do Carrascal e a Cabeça alta, em um monte de pouca elevação junto à antiga estrada do Vale de Cardigos com as coordenadas $39^{\circ} 42^{\prime} 3062^{\prime \prime} \mathrm{N}, 7^{\circ} 58^{\prime} 59$ 91”W.

É um dos seis túmulos megalíticos na freguesia de Mação, datado do $5^{\circ}$ milênio a.C. e atribuído culturalmente ao Neolítico (SCARRE, 2004, 2006). É composto de uma pequena câmara encerrada em um monte circular situado em um cume (Figura 6). A sua implantação é aparentemente isolada, dominando um amplo território, construída em xisto com planta octogonal, corredor baixo estruturado com pequenos blocos, localizada em encostas íngremes $\left(25-45^{\circ}\right)$ onde, a poucos metros do monumento, corre um pequeno ribeiro; os objetos encontrados são escassos (OOSTERBEEK, 2008).

A primeira fase do monumento é atribuída ao $5^{\circ}$ milénio BC (SCARRE; OOSTERBEEK, 2010).

\section{Anta de Lajinha 2006}

section across mound

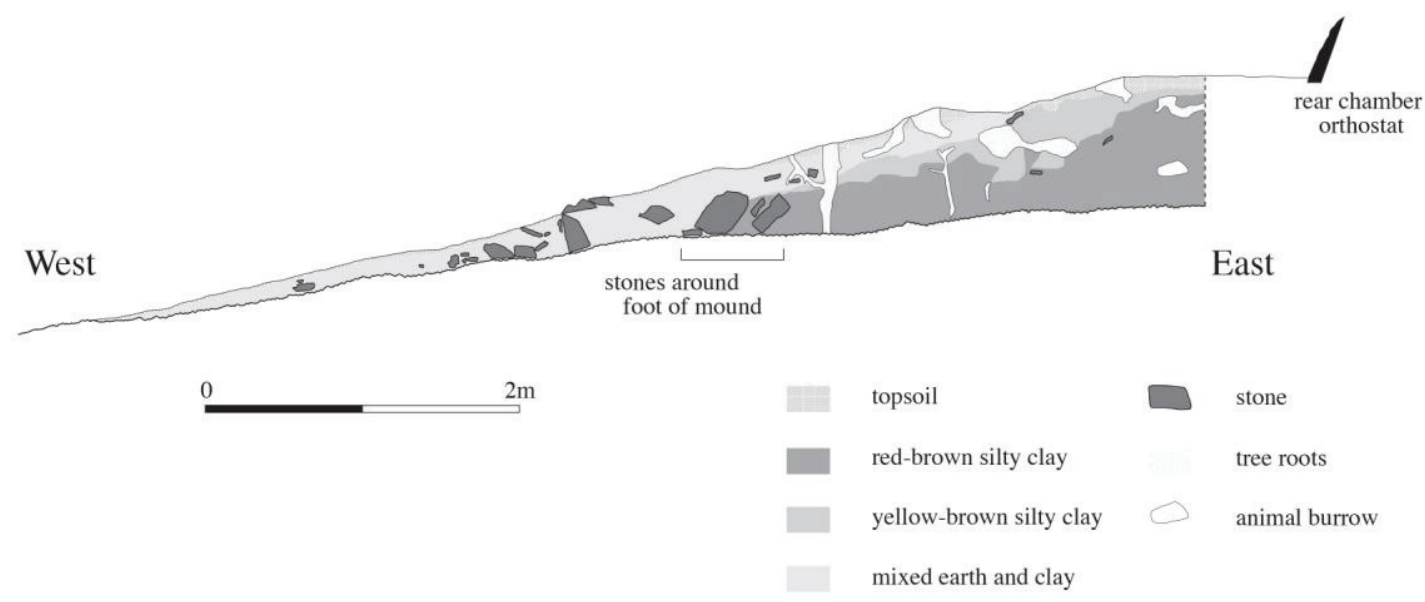

Figura 6 - Perfil estratigráfico da Anta da Lajinha)

Fonte: Scarre; Oosterbeek (2010).

\section{Depósitos de aluvião}

\section{Alvega}

Alvega, pertencente ao concelho de Abrantes, situa-se à margem sul (esquerda) do Tejo, na fronteira entre o Alto Ribatejo e as Beiras. As coordenadas do depósito de aluviões estudado são $39^{\circ} 28^{\prime} 36$ 27” $\mathrm{N}$ e $8^{\circ} 01^{\prime} 3003^{\prime \prime} \mathrm{W}$.

$\mathrm{O}$ rio corre aos $29 \mathrm{~m}$ de altitude. $\mathrm{O}$ canal atual do Tejo vira abruptamente para noroeste em ângulo reto, deixando uma grande área de várzea 
antiga e depósitos de paleocanais no lado sudoeste do rio. Quando os diques históricos foram feitos nos anos 50 do século XX, provavelmente para conter ou canalizar as águas em momentos de cheias, deu-se o abandono do antigo canal (antigo leito do Tejo), representado por bancos cascalhentos. O perfil estudado, da base para o topo, apresenta um nível cimentado ferruginoso de seixos, areias grosseiras e seixos na margem atual e, uma espessa alternância de areias lavadas, areias argilosas e camadas com material orgânico, madeira e turfa. Durante os trabalhos de campo, foi claramente identificado o canal antigo e um afloramento na margem sudoeste do rio com uma exposição de aproximadamente 10 $\mathrm{m}$ de areias laminadas, intercaladas com níveis argilolimosos com grande componente orgânica. Na base, identificou-se um depósito areno-conglomerático, com cimento ferruginoso, de cor alaranjada. Acredita-se ser um terraço fluvial Pleistocênico.

Estes depósitos provavelmente correspondem aos episódios úmidos da Pequena Idade do Gelo (VIS et al., 2010a, 2010b).

\section{Outeiro do Pedro}

Outeiro do Pedro pertence ao concelho de Mação e situa-se à margem norte (direita) do Tejo, de frente a Alvega, com as coordenadas M - 39 $28^{\circ}$ $25,6^{\prime \prime} \mathrm{N}$ e P- $8^{\circ} 03^{\prime} 29,5^{\prime \prime}$ e uma altitude entre os 40 e $55 \mathrm{~m}$. Realizaram-se variadas sondagens mecânicas na planície aluvial do Tejo, localizadas a menos de $50 \mathrm{~m}$ do atual leito do rio. A profundidade média atingida foi de cerca de $3 \mathrm{~m}$, tendo-se identificado o enchimento areno-siltoso e o soco metamórfico. Foram coletadas amostras para caracterização granulométrica, identificação de minerais argilosos e análises paleobotânicas. Os sedimentos são bastante heterogêneos, constituídos de siltes grosseiros, areias muito finas e grosseira a muito grosseira, podendo representar deposição aluvional, depósitos eluviais e coluviões.

\section{Resultados laboratoriais}

Analisando os dados obtidos nos gráficos (Figura 7), foi possível identificar conjuntos de amostras distintos apresentando granulometrias desde argilas a areias grosseiras, as quais, no geral, estavam mal calibradas e com assimetria muito positiva.

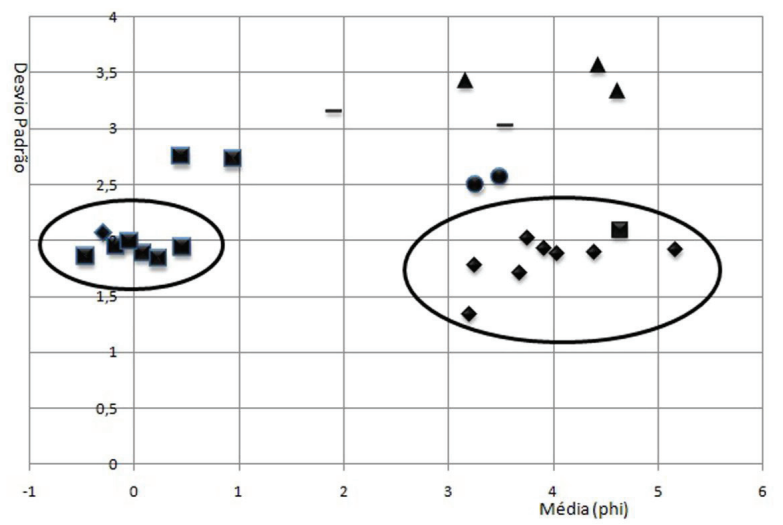

Figura 7 - Gráfico de parâmetros granulométricos - média-desvio-padrão. Legenda: $\Delta$ Lajinha (LAG); - Amoreira (AMR); • Santa Margarida da Coutada (SMAC); a Alvega (ALV); $\diamond$ Ribeira Atalaia (ATL) Fonte: Elaborada pelos autores (2010).

Salvaguardando áreas diferentes, os resultados dimensionais obtidos (camada C) AMR e SMAC são similares, o que apresenta certa coerência, pois os sítios localizam-se em frente um ao outro, em margens opostas do Tejo. Embora se localizem na mesma área, curiosamente apresentam minerais de argila diferentes, o que provavelmente indica uma origem diferente. Grosso modo, os resultados obtidos enquadram-se nas condições de regime de sedimentação destes depósitos. O primeiro conjunto, com granulometrias mais grosseiras, corresponde a depósitos de coluvião, podendo ocorrer pontualmente variações de amostra para amostra. O conjunto de granulometrias mais finas corresponde a depósitos de aluvião e eólicos, assim como os sedimentos dos depósitos eluviais antrópicos. De referir que a consistência na forma das curvas de frequência relativa, das amostras produzidas por processos similares de sedimentação é notória.

$\mathrm{Da}$ análise dos gráficos de resultados sedimentológicos apresentados, pode-se afirmar que, macroscopicamente e genericamente, os depósitos apresentam-se heterométricos, argiloconglomeráticos imaturos de tonalidade amareloavermelhada, com seixos de quartzito, arenito, quartzo e xisto normalmente rolados com dimensões até $15 \mathrm{~cm}$ e com matriz que é aproximadamente $60 \%$ da massa total. 
No pormenor, a análise granulométrica veio precisar aquilo que as observações macroscópicas indicavam pois, para o total das amostras, a fração fina varia de 0,028 a 1,223 $\mathrm{mm}$, contendo também frações grosseiras até seixos e clastos $(15 \mathrm{~cm})$. As frações arenosas mostraram uma tendência para distribuições unimodais, embora se tenha observado plurimodais, os valores de mediana estão compreendidos entre 0,05 e 1,40 mm, denotando-se a importância de areias muito grosseiras.

\section{Discussão}

Obtiveram-se datações por metodologias diversas em sítios arqueológicos dominados por processos de formação diferentes.

Sítios de ocupação a céu aberto (Ribeira da Atalaia, Santa Margarida Coutada e povoado da Amoreira), monumentos megalíticos em diferentes estados de preservação (Anta 1 de Val da Laje, Anta da Lajinha), depósitos de gruta (Cadaval, Caldeirão, Ossos) e um depósito de aluvião correlacionado estratigraficamente com achados arqueológicos. Da Ribeira da Atalaia, salientam-se as datações dos coluvióes com aproximadamente 25 mil anos, sendo as datações mais antigas utilizadas neste estudo. Sedimentos de origem eólica atribuíveis às fases secas do tardi-glaciar.

Dos depósitos de gruta-necrópole da região de Tomar, realçam-se as datações da gruta do Cadaval que apontam para uma sua utilização aos 6.000 BP.

A análise das datações relativas aos monumentos megalíticos da região aponta pela expansão destes em complexos de necrópoles (Anta de Val da Laje) e, mais tardiamente, por monumentos isolados na paisagem (Anta da Lajinha, Anta da Foz do Rio Frio). A Anta da Lajinha, ainda bem preservada, apresenta uma interpretação curiosa uma vez que são identificadas claramente as fases construtivas do monumento (câmara, corredor, mamoa), ocupado no Neolítico. Os resultados para o Povoado de Santa Margarida da Coutada, segundo Cruz (2011), apresentam dados consistentes com o período Calcolítico; em Alvega, os depósitos corresponderiam às fases históricas pós-medievais.

Concluindo, estes resultados indicam o potencial dos sítios pré-históricos da região, relacionados com períodos tardios; mas, confirmase, também, a atividade no Neolítico. Os dados obtidos apoiam a hipótese de que no período entre os 25.000 e $8.000 \mathrm{BP}$ ocorreram diversos episódios frios que originaram depósitos coluviais e eólicos, não suportando a hipótese de estabilidade climática formulada por Roche $(1971,1982)$.

Identifica-se, no período entre os 10.000$7.600 \mathrm{BP}$, um clima mais úmido, e este origina processos de pedogênese.

Os monumentos megalíticos da área estão relacionados com o período posterior (7.500-5.500 BP) que é marcado por uma melhoria no clima, mais quente, em que a sedimentação aumenta, provocando o assoreamento dos rios e a progressiva degradação da vegetação preexistente com períodos de clima muito mais úmidos e, progressivo aquecimento húmido ( 6.000 BP).

$\mathrm{Da}$ análise da estratigrafia, conclui-se que no $6^{\circ}$ milénio $\mathrm{AC}$ grupos de caçadores recoletores altamente móveis ocuparam o vale do Tejo. Ainda que não se tenham encontrado indústrias in situ, averiguaram-se artefatos na superfície. No $5^{\circ}$ milénio AC, grupos ainda móveis, porém mais interconectados, ocuparam o vale e marcaram o território construindo monumentos megalíticos. No $4^{\circ}$ milénio, há reocupação de alguns monumentos megalíticos, associados a um importante crescimento demográfico e ao cultivo de vegetais e cereais. Embora no $3^{\circ}$ e $2^{\circ}$ milénio as evidências sejam escassas, há registro de reutilização da Anta 1 do Vale da Laje na Idade do Bronze inicial.

Da Anta da Lajinha, pode-se afirmar que LAG-C é uma camada anterior à construção do monumento, em que o sedimento é essencialmente composto por silte muito grosseiro, correspondendo à desagregação do xisto, de dispersão pobre, simétrica e leptocúrtica aparentando ser uma camada natural.

Os resultados dos sedimentos recolhidos em Alvega no depósito Holocênico de referência, apresentam um conjunto granodecrescente (Alv 5, Alv 6, Alv 7) que indica variações na posição do canal do Rio Tejo; os conjuntos de sedimentos de granulometrias muito finas (Alv 2, Alv 3 ) representam fácies de decantação, indicando diminuição de energia e de transporte. 


\section{Conclusão}

$\mathrm{Na}$ ótica da transição para o agropastoralismo, a relação entre as variações dos depósitos sedimentares e as variações ambientais pode servir de base de discussão sobre as dinâmicas de ocupação humana e as paisagens (BURBIDGE et al., 2014). Infelizmente, não possuímos sequências estratigráficas contínuas e completas para todo o período considerado (Pleistocênico final - Holocênico) pelo que nos servimos de depósitos de diferente natureza e origem para uma tentativa de reconstrução cronostratigráfica e paleoambiental, homogeneizando os dados estratigráficos e sedimentológicos com as datações disponíveis e os vestígios culturais.

É de salientar que existem três categorias de depósitos que são dificilmente correlacionáveis diretamente: os depósitos naturais subaéreos, os depósitos de grutas e os de origem antrópica (ou fortemente influenciados/alterados pelas atividades humanas). Sedimentológicamente, as análises destes últimos não podem ser correlacionadas com os depósitos naturais. Em particular, a caracterização de sedimentos relacionados com os monumentos megalíticos deve ser realizada em zonas da envolvente do sítio, uma vez que todo o sistema deposicional in situ é de origem antrópica e/ou resultado de alteração dos esteios; consequentemente não é possível uma caracterização do ponto de vista deposicional. Os estudos sedimentológicos e estratigráficos realizados, integrados com os dados de outras áreas, permitem relacionar os depósitos com a evolução das condições paleoambientais (Tabela 1).

Tabela 1 - Correlação de depósitos e períodos climáticos com os sítios arqueológicos da região

\begin{tabular}{|c|c|c|c|}
\hline Depósitos & Período climático & Datações (BP) & Sítios \\
\hline Coluviões & Glaciar & 25000 & Ribeira da Atalaia \\
\hline Eólico & $\begin{array}{c}\text { Tardi-glaciar e } \\
\text { Pré-Boreal inicial }\end{array}$ & $14000-11000$ & $\begin{array}{c}\text { Santa Cita, } \\
\text { Santa Margarida Coutada }\end{array}$ \\
\hline Aluvião & Pré-Boreal final & 9000 & Amoreira \\
\hline Coluvião & Final Boreal e Atlântico inicial & 7500 & Amoreira \\
\hline $\begin{array}{l}\text { Enchimento } \\
\text { cavidades cársicas }\end{array}$ & Boreal a Sub-boreal & $8000-4000$ & Várias grutas \\
\hline Eluvial & Atlântico e Sub-boreal & $6000-3800$ & Anta da Laginha \\
\hline $\begin{array}{l}\text { Antrópico/ } \\
\text { Paleosolo }\end{array}$ & Atlântico & 6000 & Anta 1 Vale da Laje \\
\hline Coluvião & Sub-boreal & $5000-2000$ & Santa Margarida da Coutada \\
\hline Aluvial & $\begin{array}{c}\text { Sub-Atlântico } \\
\text { (Pequena Idade Gelo) }\end{array}$ & 1500-1800 D.C. & $\begin{array}{c}\text { Alvega, } \\
\text { Outeiro do Pedro, }\end{array}$ \\
\hline
\end{tabular}

Fonte: Elaborada pelos autores (2010).

Os resultados analisados sobre o assunto indicam um período de formação de coluviões no período glaciar (pelo menos aos 25.000), pela formação coluvionar antes do pós-Glaciar (MUNOZ; REGO; GOMEZ-ORELLANA, 2007). No Tardiglaciar até ao Holocênico inicial, subsistem várias evidências de depósitos de origem eólica (Quinta do Paço, SMAC e SCT, esta última sem datações absolutas). No final do pré-Boreal, há um depósito (AMR-C) de origem aluvial talvez associado com a última transgressão. No final do período Boreal/início do período Atlântico, foram reconhecidos depósitos coluvionares provavelmente correspondentes a um período de diminuição da cobertura arbórea associado a uma oscilação climática seca ou ao começo das práticas agrícolas, processos de degradação da floresta anteriores ao estabelecido para as comunidades agropastoris (ALLUÉ, 2000). É sobretudo no Holocénico médio (do Boreal ao Sub-Boreal) que se desenvolvem, nesta região, os depósitos de origem eluvial, de preenchimento de gruta e de natureza antrópica. 
No final do Sub-boreal, foi descrito um depósito coluvionar (SMAC) que pode ser relacionado com o período frio do final da Idade do Ferro. Os últimos depósitos com significativa espessura ou com relativa importância ambiental ocorrem já na pequena Idade do Gelo (Subatlântico). O estudo realizado mostra um elevado grau de coerência entre o tipo de depósitos e as variações climáticas por um lado e as dinâmicas agropastoris por outro. Foi ainda possível verificar que os depósitos coluvionares estão associados aos períodos frios, os eólicos ao tardiglaciar e, uma intensa ação eluvial/pedogenética a atividades antrópicas (Tabela 1).

\section{Referências}

ALLUÉ, E. Pollen and Charcoal analysis from archaeological sites from the Alto Ribatejo (Portugal). Arkeos: perspectivas em diálogo, Tomar, n. 9, p. 37-58, 2000.

BICHO, N. F.; FERRING, C. O sítio arqueológico de Santa Cita, Tomar: as intervenções arqueológicas de 1990 a 1997. Arkeos: perspectivas em diálogo, Tomar, n. 11, p. 71-88, 2001.

BURBIDGE, C.; TRINDADE, M.; DIAS, M.; OOSTERBEEK, L.; SCARRE, C.; ROSINA, P.; CRUZ, A.; CURA, S.; CURA, P.; CARON, L.; PRUDÊNCIO, M.; CARDOSO, G.; FRANCO, D.; MARQUES, R.; GOMES, H. Luminescence dating and associated analyses in transition landscapes of the Alto Ribatejo, central Portugal. Quat. Geochronol, n. 20, p. 65-77, 2014.

CRUZ, A. R. Amoreira: trabalhos de emergência no IP6. Teckne, Tomar, n. 1, p. 28-37, 1995.

Vale do Nabão. Do Neolítico à Idade do Bronze. Arkeos: perspectivas em diálogo, Tomar, n. 3, p. 33-46, 1997.

CRUZ, A. R. SMAC Santa Margarida da Coutada. Revista on line Ângulo, 2006. Disponível em: <http://www.cda.ipt.pt/?pagina=vinculo_ cta\&seccao $=$ Angulo_-_Repositorio_Didactico $>$. Acesso em: 20 nov. 2015.
A Pré-História recente no vale do Baixo Zêzere - Vol. 1. 1. ed. Tomar: CEIPHAR - Centro Europeu de Investigação da Pré-História do Alto Ribatejo, 2011.

; OOSTERBEEK, L. Amoreira. Revista online Ângulo, 2005. Disponível em: < http://www. cda.ipt.pt/?pagina $=$ vinculo_cta\&seccao $=$ Angulo_-Repositorio_Didactico. Acesso em: 20 nov. 2015.

CURA, S.; CRUZ, A. R; OOSTERBEEK, L.; ROSINA, P. As indústrias Macrolíticas do Alto Ribatejo: o caso do sítio da Amoreira. Actas del I Congresso Congresso peninsular de Estudantes de Prehistoria. Tarragona, 2004.

CURA, S.; GRIMALDI, S. The intensive quartzite exploitation in Midlle Tagus Valley Pleistocene open air sites: The example of Ribeira da Ponte da Pedra. In: GRIMALDI, S.; CURA, S. (Ed.). Technological Analysis on Quartzite Exploitation, Proceedings of the XV World Congress UISPP (Lisbon, 4-9 September 2006). BAR Int, 2009. p. 49-56.

DAVEAU, S. Portugal Geográfico. Lisboa: Edições Sá da Costa, 1995.

DIAS, M. I.; PRUDÊNCIO, M. I.; FRANCO, D.; CURA, S.; GRIMALDI, S.; OOSTERBEEK L.; ROSINA P. Luminescence dating of a fluvial deposit sequence: Ribeira da Ponte da Pedra - Middle Tagus Valley. Quaternary Geochronology, Portugal, n. 20, p. 65-77, 2009.

DREWETT, P.; OOSTERBEEK, L.; CRUZ, A. R.; FÉLIX, P. Anta 1 de Val da Laje. 1989/1990. The excavation of a passage grave at Tomar (Portugal). Bulletin of the Institute of Archaeology, London, n. 28, p. 133-148, 1992.

GONÇALVES, F;:ZBYSZEWSKI, F.; CARVALHOSA, A; COELHO, A. P. Carta Geológica de Portugal na escala de 1/50.000 - Notícia Explicativa da Folha 27-D (Abrantes). Direcção-Geral de Geologia e Minas - Serviços Geológicos de Portugal, Lisboa, p. 20-37, 1979.

LUSSU, T.; ROSINA, P.; OOSTERBEEK, L.; COSTA, F. O Musteriense de Santa Cita (Tomar, Alto Ribatejo, 
Portugal): investigação e conservação. Arkeos: perspectivas em diálogo, Tomar, n. 11, p. 13-70, 2001.

MARTINS, A. A.; CUNHA, P. P.; MATOS, J.; GUIMOMAR, N. Quantificação da incisão do rio Tejo no sector entre Gavião e Chamusca, usando os terraços fluviais como referências geomorfológicas. Publicações da Associação Portuguesa de Geomorfólogos, Braga, v. VI, p. 83-86, 2009.

MUNOZ, S. C.; REGO, P.; GOMEZ-ORELLANA, L. LateWurm and early Holocene in the mountains of northwest Iberia: biostratigraphy, chronology and tree colonization. Veget. Hist. Archaeobot., n. 16, p. 223-240, 2007.

OOSTERBEEK, L. Echoes from the East: the Western Network. North Ribatejo (Portugal): an insight to unequal and combined development, 7.000-2.000 B.C. 1994. Tese (Doutorado em Arqueologia) Universidade de Londres, 2, Londres, 1994.

Paisagens de Transição: Povoamento, tecnologia, e cronoestratigrafia da transição para o agro-pastoralismo no Centro de Portugal. Arkeos: perspectivas em diálogo, Tomar, n. 22, p. 173-180, 2008.

PEREIRA, T.; CARVALHO, A. F. Abrupt technological change at the $8.2 \mathrm{ky}$ cal BP climatic event in Central Portugal. The Epipalaeolithic of Pena d’Água Rockshelter. Changement technologique abrupt lors lévénement climatique $8.2 \mathrm{ky}$ cal BP dans le centre du Portugal. L’épipaléolithique de l'abri Pena d'Água. C. R. Palevol, n. 14, p. 423-435, 2015.

RIBEIRO, O.; LAUTENSACH, H.; DEVEAU, S. Geografia de Portugal - Vol. I e II. Lisboa: Ed. João Sá da Costa, 1991.

ROCHE, J. Le climat et les faunes du Paléolithique Moyen et Supérieure de la province d'Estremadura. Actas do II Congresso Nacional de Arqueologia Ministério da Educação Nacional, Junta Nacional da Educação, v. 1, p. 39-50, 1971.

A organização do espaço numa estação mesolítica portuguesa: Moita do Sebastião, Muge. Arqueologia, Porto, n. 6, p. 4-10, 1982.
ROSINA, P.; GOMES, H.; CARRONDO, J.; OOSTERBEEK, L.; CURA, S.; GOMES, J. Análise sedimentológica dos depósitos coluvionares do sítio arqueológico da Ribeira da Atalaia. Contribuição para uma interpretação geo-arqueológica. Livro de Resumos da VII Reunião do Quaternário Ibérico, Faro, Portugal, p. 215-218, 2009.

ROSINA, P.; VOINCHET, P.; BAHAIN, J. J.; CRISTOVÃO, J.; FALGUÉRES, C. Dating the onset of Lower Tagus River terrace formation using electron spin resonance. Journal of Quaternary Science, v. 29, n. 2, p. 153-162, 2014.

SCARRE, C. Displaying the Stones: the Materialità of Megalithic Monuments. In: DEMARRAIS, E.; GOSDEN, C.; RENFREW, C. (Ed.). Rethinking Materiality-the engagement of mind with the material world. Cambridge: University Press, 2004. p. 141-152.

The Human past. World prehistory e development of human societies. London: Thames \& Hudson; British Library, 2006.

.; OOSTERBEEK, L. The Megalithic tombs of the Middle Tagus basin and agro-pastoral origins in Western Iberia. In: STER, T. A.; HEGEWISCH, M. (Ed.). On Pre- and Earlier History of Iberia and Central Europe. Studies in honour of Philine Kalb Bonn, Habelt-Verlag, 2010. p. 97-110.

VIS, G.; KASSE, C.; KROON, D.; JUNG, S.; ZUUR, H.; PRICK, A. Late Holocene Sedimentary Changes in Floodplain and Shelf Environments of the Tagus River (Portugal). Proceedings of the Geologists' Association, Portugal, v. 121/122, p. 203-217, 2010a.

VIS, G.; BOHNCKE, S. J. P.; SCHNEIDER, H.; KASSE, C.; COENRAADS-NEDERVEEN, S.; ZUURBIER, K.; ROZEMA, J. Holocene flooding history of the Lower Tagus Valley (Portugal). Journal of Quaternary Science, Portugal, v. 25, p. 1222-1239, 2010b. 